\section{Lack of Small Family Norms in low Resource Settings}

\section{Abstract}

Background: Fertility is determined by many factors, so there are variations in pregnancies, births. Family size varies within, between societies. Socioeconomic status, environment, culture, education, couples' understanding, every day life play vital roles.

Objectives: Present study was done to know sterilization practices by couples of rural, tribal communities of Melghat region Amravati, Maharashtra, India.

Materials and methods: Study subjects were 520 married women of 20-35 years. If non pregnant then with one or more births, at least one live child. If pregnant then with second pregnancy onwards, willing to give consent for providing desired information as per predesigned, pretested questionnaire in local language.

Results: Of 520 women, 198 had one live child, no one had sterilization. There was hardly any birth spacing/planning, except occasional use of condom by educated, very few. Of 322 women with 2 or more live children, only 77 (26\%) had sterilization, no vasectomy. Two hundred women had 2 live children, $43(21.5 \%)$ of them had sterilization, 122 had $>2$ live children, only $34(28 \%)$ had sterilization. Only $17(13.9 \%)$ of 122 women had sterilization with 1 male and 1 female child, none with no male child, irrespective of number of female children, Mostly women had sterilization after 3 male children, 60 of 77 (77.92\%) had sterilization after 2 or more male children.

Conclusion: Fertility was high creating more problems for tribal communities with extremely low resources. Only women underwent sterilization. Not only son was essential, there was desire of more than 2 male children. It is essential to create awareness about advantages of small families for health, social, economic aspects and about gender equity.

Keywords: Small family norms; Son preference; Sterilization

\section{Chhabra S*}

Department of Obstetrics and Gynecology, Mahatma Gandhi Institute of Medical Sciences, Wardha, Maharashtra, India

\section{*Corresponding author: Chhabra S}

\section{chhabra_s@rediffmail.com}

Department of Obstetrics and Gynecology, Mahatma Gandhi Institute of Medical Sciences, Wardha, Maharashtra, India.

Tel: 917152284342

Citation: Chhabra S (2018) Lack of Small Family Norms in low Resource Settings. J Contracept Stud Vol.3 No.1:1

\section{Background}

Human fertility is affected by many factors. So there are variations in pregnancies, births, in communities. Acceptance of planned family norms vary in couples, families, within and between societies. Socioeconomic class, environment, culture, education, customs, habits, understanding of couples', and their everyday life play vital roles, affect acceptance of planned family norms. The high fertility rates leading to the growth of population is a major hindrance towards the national development. WHO defined Family planning as "a way of thinking and living that is adopted voluntarily, upon the basis of knowledge, attitudes and responsible decisions by individuals and couples, in order to promote the health and welfare of the family groups and thus contribute effectively to the social development of the country" [1]. India was the first country to launch a well-defined family planning (FP) programme in 1951 with the major objective to balance the population. However India's current demography is characterized by high fertility with moderate mortality rates which is leading to population growing rapidly, about 18 million people being added to it annually with 2.1 per cent increase per annum. Persisting high fertility and the considerable decline in mortality are the main causes of the continuing high rate of growth of India's population. There are regions where people 
do not even think about planning family size. So India is the second most populous country in the world. Despite constant efforts by the government, unmet needs still remain high [2]. Understanding of the gap and mismatch between expressed favourable attitude towards the small family norms, knowledge and practices of family planning amongst Indian couples continues to be a research agenda.

Maharashtra Province of India is one of the few states with better health indicators. Overall small family norms are better accepted. However, Melghat region of Amravati district of Maharashtra province of India, a hilly region with dense forests, known for tiger reserve, wild life sanctuary is also known for high maternal, neonatal, infant and child mortality. There are around 325 villages in the region. Health and human development are the key concerns. At least one child under six years, dies every day and nearly two women die every month giving birth to a child. It is essential that communities realise that planning family size with properly spaced children can help them have the desired number of children, which as a result will improve the health of mothers and children somewhat and contribute to their development and the nation's social and economic development. However, it seems 'desire or no desire' of having more children's is not even thought, why needs research.

\section{Objectives}

Present study was done to know the sterilization practices of couples of rural tribal communities of Melghat region of Amravati district of Maharashtra, India.

\section{Materials and Methods}

Randomly a bunch of 52 villages (15\% of the villages in Melghat region) was selected, keeping in mind the distance from the health facility already created, togetherness of the villagers for getting the desired information and future services. Communitybased ethnographic method was used. Tool was developed keeping in mind the international norms with regard to research involving human respondents. Ethics committee's approval was taken. Informed consent of the respondents was taken prior to their participation in the study. And of the 52 villages, every $10^{\text {th }}$ house was visited with the scope for modification, depending on the number of houses in a village and available women as per inclusion criteria. Study subjects were finally 520 married women of 20 to 35 years, with one or more live babies, if pregnant then also with at least second pregnancy onwards and willing to give consent for providing the desired information as per the predesigned and pretested questionnaire.

Of 520 women, 373 (72\%) were of $20-25$ years and of them, 52 (14\%) were illiterate, 148 (40\%) had primary, $142(38 \%)$ secondary school, 27 (7.2\%) higher secondary education, $3(0.8 \%)$ graduates and one had postgraduate degree (0.2\%). Of the 138 (26\%) women between 26-30 years, 22 (16\%) were illiterate, 28 (20.28\%) had primary school education, 71 (51.45\%) secondary, $14(10.14 \%)$ higher secondary education, two (1.4\%) graduation and one had post graduate degree $(0.7 \%)$. Of the $9(2 \%)$ women of $31-35$ years, there was one illiterate $(11 \%)$, seven had primary
(78.0\%) and one secondary school education (11\%). Over all $373(72 \%)$ women were of $20-25$ years, $138(26 \%)$ between 26 30 years and $9(2 \%)$ between $31-35$ years and $14 \%$ illiterate, in this era, only $1 \%$ graduate and $0.4 \%$ had postgraduate degree. More young women had better education. Most women belonged to lower economic class (Modified Kuppuswami's 2009 classification). Focus group discussions (FGDs) were also done with same tool, but questions were modified for asking in a group and there was no bar of age and birth interval. All the women willing were welcome, $10-15$ at a time.

\section{Results}

Of 520 women, only 77 (15\%) had undergone sterilization. There were 198 [(one with 3 births but only 1 live child and 197 with one birth), with one live child (102 male and 96 female)], none had undergone sterilization, neither husband nor wife. Over all 322 women had 2 or more children and only 77 (26\%) of them had undergone sterilization, no husband had vasectomy. Two hundred women had 2 live children, 43 (21.5\%) of them had sterilization, One hundred twenty two women had more than 2 live children, of which also only 34 (28\%) had sterilization only $17(13.97 \%)$ of 122 women who had at least 1 male child had sterilization. None had sterilization if they had only female children, irrespective of number of live female children. Most of the women had sterilization after at least 2 male children, Sixty of 77 (77.92\%) women who had sterilization had either 2 or more children, one or more male children (Tables 1 and 2). Overall of the 43 women who had sterilization with 2 living children, only 17 (39.5\%) had one male child, rest had two.

Of 200 women who had 2 children, 43 (22\%) underwent sterilization, seventy three had one male and one female child, of which only 17 (23\%) had sterilization, 74 had 2 male children of which 26 (35\%) had sterilization. Eighty four women had 3 births (12 with 3 female children, none had sterilization, one had only one live male child, ( 2 children died) and she did not get sterilization. Nine had 3 male children, 7 (78\%) of them had sterilization, 25 had 1 female and 2 male children, 7 (28\%) of them had sterilization, 37 had 2 female children and 1 male child, none had sterilization. Twenty eight women had 4 births ( 2 had 4 female children, none had sterilization, 8 had 1 female 3 male children and all had undergone sterilization. One had 1 female and 2 male live children ( 1 died) and did not get sterilization done. And all 6 women with 2 female and 2 male children had undergone sterilization. Of 7 with 3 female and 1 male child, none had sterilization. One had 1 male and 1 female live child (lost 2) and did not get sterilization done, 3 had 1 male and 2 female live children (each lost one), none had sterilization. Seven women had 5 births, 4 had 2 female and 3 male children, all had undergone sterilization, 2 had 2 female and 2 male live children, (each lost one), of which 1 had undergone sterilization and one had 4 female children and 1 male child, did not get sterilization. Three women had 6 births, one had 2 male and 4 female children, did not get sterilization, one woman had 3 male and 3 female children, had sterilization and one had 1 male and 4 female live children (one died) and did not get sterilization. Two women had seven births, one had 2 male and 5 female children, did not get 
Table 1 Age, parity and sterilization.

\begin{tabular}{|c|c|c|c|c|c|c|c|c|c|c|c|c|}
\hline \multirow{3}{*}{ Parity } & \multirow{3}{*}{$\begin{array}{l}\text { Sex of } \\
\text { baby }\end{array}$} & \multirow{3}{*}{ Live children } & \multirow{2}{*}{\multicolumn{3}{|c|}{$\begin{array}{l}\text { 20-25 years } \\
\text { Sterilization }\end{array}$}} & \multicolumn{3}{|c|}{$26-30$ years } & \multicolumn{3}{|c|}{$31-35$ years } & \multirow{3}{*}{ Total } \\
\hline & & & & & & & iliza & & & terilizati & & \\
\hline & & & Yes & No & Total & Yes & No & Total & Yes & No & Total & \\
\hline \multirow{2}{*}{ Para 1} & $M$ & $1 \mathrm{M}$ & - & 88 & 88 & - & 13 & 13 & - & - & - & 101 \\
\hline & $\mathrm{F}$ & $1 \mathrm{~F}$ & - & 95 & 95 & - & 1 & 1 & - & - & - & 96 \\
\hline \multirow{3}{*}{ Para 2} & $1 \mathrm{M}+1 \mathrm{~F}$ & $1 \mathrm{M}+1 \mathrm{~F}$ & - & 46 & 46 & 16 & 10 & 26 & 1 & - & 1 & 73 \\
\hline & $2 \mathrm{M}$ & $2 \mathrm{M}$ & 18 & 34 & 52 & 8 & 14 & 22 & - & - & - & 74 \\
\hline & $2 \mathrm{~F}$ & $2 \mathrm{~F}$ & - & 44 & 44 & - & 8 & 8 & - & - & - & 52 \\
\hline \multirow{5}{*}{ Para 3} & $3 F$ & $3 F$ & - & 8 & 8 & - & 4 & 4 & - & - & - & 12 \\
\hline & $3 \mathrm{M}$ & $3 \mathrm{M}$ & 5 & 1 & 6 & 1 & 1 & 2 & 1 & - & 1 & 9 \\
\hline & $1 F+2 M$ & $1 \mathrm{M}$ & - & - & - & - & - & - & - & 1 & 1 & 1 \\
\hline & $1 F+2 M$ & $1 F+2 M$ & - & 10 & 10 & 6 & 8 & 14 & 1 & - & 1 & 25 \\
\hline & $2 \mathrm{~F}+1 \mathrm{M}$ & $2 F+1 M$ & - & 9 & 9 & - & 27 & 27 & - & 1 & 1 & 37 \\
\hline \multirow{7}{*}{ Para 4} & $4 \mathrm{~F}$ & $4 \mathrm{~F}$ & - & 2 & 2 & - & - & - & - & - & - & 2 \\
\hline & $1 F+3 M$ & $1 F+3 M$ & 5 & - & 5 & 3 & - & 3 & - & - & - & 8 \\
\hline & $2 \mathrm{M}+2 \mathrm{~F}$ & $2 M+1 F$ & - & - & - & - & 1 & 1 & - & - & - & 1 \\
\hline & $2 \mathrm{~F}+2 \mathrm{M}$ & $2 \mathrm{~F}+2 \mathrm{M}$ & - & - & - & 6 & - & 6 & - & - & - & 6 \\
\hline & $3 \mathrm{~F}+1 \mathrm{M}$ & $3 F+1 M$ & - & 3 & 3 & - & 4 & 4 & - & - & - & 7 \\
\hline & $1 \mathrm{M}+3 \mathrm{~F}$ & $1 \mathrm{M}+1 \mathrm{~F}$ & - & - & - & - & - & - & - & 1 & 1 & 1 \\
\hline & $2 M+2 F$ & $1 \mathrm{M}+2 \mathrm{~F}$ & - & - & - & - & 3 & 3 & - & - & - & 3 \\
\hline \multirow{3}{*}{ Para 5} & $2 F+3 M$ & $2 F+3 M$ & 2 & - & 2 & 1 & - & 1 & 1 & - & 1 & 4 \\
\hline & $2 M+3 F$ & $2 \mathrm{M}+2 \mathrm{~F}$ & - & - & - & 1 & 1 & 2 & - & - & - & 2 \\
\hline & $4 \mathrm{~F}+1 \mathrm{M}$ & $4 \mathrm{~F}+1 \mathrm{M}$ & - & - & - & - & 1 & 1 & - & - & - & 1 \\
\hline \multirow{3}{*}{ Para 6} & $2 M+4 F$ & $2 M+4 F$ & - & - & - & - & - & - & 1 & - & 1 & 1 \\
\hline & $3 M+3 F$ & $3 \mathrm{M}+3 \mathrm{~F}$ & - & 1 & 1 & - & - & - & - & - & - & 1 \\
\hline & $2 M+4 F$ & $1 \mathrm{M}+4 \mathrm{~F}$ & - & - & - & - & - & - & - & 1 & 1 & 1 \\
\hline \multirow{2}{*}{ Para 7} & $2 M+5 F$ & $2 M+5 F$ & - & 1 & 1 & - & - & - & - & - & - & 1 \\
\hline & $2 M+5 F$ & $1 \mathrm{M}+4 \mathrm{~F}$ & - & 1 & 1 & - & - & - & - & - & - & 1 \\
\hline \multicolumn{3}{|c|}{ Total } & 30 & 343 & 373 & 42 & 96 & 138 & 5 & 4 & 9 & 520 \\
\hline \multicolumn{3}{|c|}{$\begin{array}{l}\text { Women who have undergone } \\
\text { sterilization }\end{array}$} & 30 & - & - & 42 & - & - & 5 & - & - & 77 (15\%) \\
\hline \multicolumn{3}{|c|}{ No. of women>2 live children } & \multicolumn{3}{|c|}{48} & \multicolumn{3}{|c|}{68} & \multicolumn{3}{|c|}{6} & 122 \\
\hline \multirow{2}{*}{\multicolumn{3}{|c|}{$\begin{array}{c}\text { No of women with }>2 \text { children who } \\
\text { had sterilization }\end{array}$}} & \multirow{2}{*}{\multicolumn{3}{|c|}{$12(25 \%)$}} & \multirow{2}{*}{\multicolumn{3}{|c|}{$18(26.5 \%)$}} & \multirow{2}{*}{\multicolumn{3}{|c|}{$4(66.6 \%)$}} & 34 \\
\hline & & & & & & & & & & & & $-34 \%$ \\
\hline \multicolumn{3}{|c|}{ No. of women with 2 live children } & & 142 & & & 56 & & & 2 & & $200(38 \%)$ \\
\hline No. of wc & $\begin{array}{l}\text { nen with } 2 \\
\text { ad steriliza }\end{array}$ & $\begin{array}{l}\text { children who } \\
\text { tion }\end{array}$ & & $18(12.69$ & & & $(42.8$ & & & $1(50 \%)$ & & $43(21.5 \%)$ \\
\hline
\end{tabular}

sterilization and one had 1 male 4 female live children (lost 2) and did not get sterilization. Over all mostly women had sterilization when they had 3 male children. There was hardly any use of modern spacing methods, occasional educated used condom.

Out of 77 women who had sterilization, 38 (49.3\%) were of 2025 years, 9 illiterate from lower economic class, 12 had primary education, all of lower economic class, thirteen had secondary school, 12 of lower economic class, one upper lower economic status, 4 had higher secondary education, 3 lower economic status and one upper lower economic class (Table 3). Thirty four (44\%) women were of $26-30$ years and of them, 4 were illiterate (all from lower economic class), 9 had primary education (7 of lower economic class, 2 upper lower class), Eighteen had secondary school education, of them 16 were of lower economic class, 2 upper lower economic class. Three had higher secondary education (two lower economic class, one upper lower economic class). Five (6.4\%) women were of $31-35$ years, all 5 with secondary school education and from lower economic class. In FGDs women reported that they had to work hard for many hours, and had to do house hold work and work in field also and didn't have time to think of planning family. Some said more children were extra hands, some said children were god given. About husbands they said that they get weakness and also did what they wanted. Women could not tell them. Many were shy to talk about this issue. They did say that there should be spacing in children. However in FGDs also they said male children were essential for family name.

\section{Discussion}

Over all information about planned family practices of 520 rural women of tribal communities with low resources revealed quite a lot of useful information. No husband of study subjects had 
Table 2 Age and sterilization.

\begin{tabular}{|c|c|c|c|c|c|c|c|c|c|}
\hline \multirow{2}{*}{ Parity } & \multicolumn{3}{|c|}{$20-25$ years } & \multicolumn{3}{|c|}{$26-30$ years } & \multicolumn{3}{|c|}{ 31-35 years } \\
\hline & Total & Sterilization & $\%$ & Total & Sterilization & $\%$ & Total & Sterilization & $\%$ \\
\hline P2 & 142 & 18 & 13 & 58 & 24 & 41 & 1 & 1 & 100 \\
\hline P3 & 33 & 5 & 15 & 47 & 7 & 15 & 4 & 2 & 50 \\
\hline P4 & 10 & 5 & 50 & 17 & 9 & 53 & - & - & - \\
\hline P5 & 2 & 2 & 100 & 4 & 2 & 50 & 1 & 1 & 100 \\
\hline P6 & - & - & - & - & - & - & 2 & 1 & 50 \\
\hline Total & 187 & 30 & 178 & 126 & 42 & 159 & 8 & 5 & 300 \\
\hline
\end{tabular}

Table 3 Age, education, socio-economic status with sterilization.

\begin{tabular}{|c|c|c|c|c|c|c|c|c|}
\hline \multirow{2}{*}{ Age } & \multicolumn{3}{|c|}{ Education } & \multicolumn{2}{|c|}{ Women with Sterilization } & \multicolumn{3}{|c|}{ Socio-economic Status } \\
\hline & & No & $\%$ & No & $\%$ & & & \\
\hline & \multirow{2}{*}{1} & \multirow{2}{*}{43} & \multirow{2}{*}{11.52} & \multirow{2}{*}{09} & \multirow{2}{*}{02.41} & Upper Lower & 001 & \\
\hline \multirow{12}{*}{$\begin{array}{c}20-25 \text { years. } \\
373(72 \%)\end{array}$} & & & & & & Lower & 042 & 09 \\
\hline & \multirow{3}{*}{$\mathrm{P}$} & \multirow{3}{*}{136} & \multirow{3}{*}{36.46} & \multirow{3}{*}{12} & \multirow{3}{*}{03.21} & Middle & 001 & \\
\hline & & & & & & Upper Lower & 011 & \\
\hline & & & & & & Lower & 124 & 12 \\
\hline & \multirow{2}{*}{$\mathrm{S}$} & \multirow{2}{*}{129} & \multirow{2}{*}{34.58} & \multirow{2}{*}{13} & \multirow{2}{*}{03.48} & Upper Lower & 013 & 01 \\
\hline & & & & & & Lower & 116 & 12 \\
\hline & \multirow{2}{*}{ HS } & \multirow{2}{*}{023} & \multirow{2}{*}{06.16} & \multirow{2}{*}{04} & \multirow{2}{*}{01.07} & Upper Lower & 007 & 01 \\
\hline & & & & & & Lower & 016 & 03 \\
\hline & \multirow{2}{*}{ G } & \multirow{2}{*}{003} & \multirow{2}{*}{00.80} & \multirow{2}{*}{00} & & Upper Lower & 002 & \\
\hline & & & & & 00 & Lower & 001 & \\
\hline & PG & 001 & 00.26 & 00 & 00 & Lower & 001 & \\
\hline & & 335 & 89.81 & 38 & 10.18 & & 335 & 38 \\
\hline & 1 & 018 & 1304 & 04 & 289 & Upper Lower & 02 & \\
\hline & 1 & 018 & 13.04 & 04 & 2.89 & Lower & 16 & 04 \\
\hline & $P$ & & 1376 & 09 & 652 & Upper Lower & 01 & 02 \\
\hline & $P$ & 019 & 13.10 & U9 & 0.52 & Lower & 18 & 07 \\
\hline & & & 3840 & & 1204 & Upper Lower & 03 & 02 \\
\hline $26-30$ years. & $\mathrm{s}$ & 053 & 38.40 & 18 & 13.04 & Lower & 50 & 16 \\
\hline $138(26 \%)$ & & & & 03 & & Upper Lower & 04 & 01 \\
\hline & $\mathrm{HS}$ & 011 & 01.91 & U3 & U2.1/ & Lower & 07 & 02 \\
\hline & $\mathrm{G}$ & 002 & 144 & 00 & مी & Upper Lower & 01 & \\
\hline & G & UUL & 1.44 & 00 & 00 & Lower & 01 & \\
\hline & $P G$ & 001 & 0.72 & 00 & 00 & Upper Lower & 01 & \\
\hline & Total & 104 & 75.36 & 34 & 24.63 & & 104 & 34 \\
\hline & 1 & 001 & 11.11 & 0 & 0 & Lower & 01 & \\
\hline $\begin{array}{c}31-35 \text { years. } \\
009(2 \%)\end{array}$ & $P$ & 002 & 22.22 & 5 & 55.55 & Lower & 02 & 05 \\
\hline & $\mathrm{S}$ & 001 & 11.11 & 0 & 0 & Lower & 01 & \\
\hline 520 (100\%) & Total & 443 & 85.20 & 77 & 14.80 & & 443 & 77 \\
\hline
\end{tabular}

undergone vasectomy. Also with one live child, whether male or female, none had undergone sterilization. Few had sterilisation with one male and one female child. Most of the women who had sterilization had 3 live male children. The study revealed that acceptance of sterilization depended on joint decision of the family, but mostly husband and his mother decided. The female literacy had a positive impact on getting sterilization. The need of the hour was creating awareness by health workers regarding planned family, advantages of small families, awareness of the benefits. A lot of sociobehavioural research is needed. Media plays an important role in the promotion and acceptability of family planning, but has limitations in the regions like the study area with access problems and low resources. Literacy, number of living children and number of living sons influenced sterilization acceptance. Many factors needed to be analyzed for formulation of appropriate policies and desired approaches. The fertility was high and only females underwent sterilization, no men. More women who had sterilization were older women $155 \%$ of all of 31-35 years, $30 \%$ of all of $26-30$ years and $8.0 \%$ of all of $20-25$ years). None of the women underwent sterilization if they had only female children, irrespective of number, even 7 live female children in this era. Only 17 , of 520 women had sterilization after having 2 children with one male child and most of the women who had sterilization had it after 3 live male children. 
Edmeades et al. [3] reported that sterilization is motivated by son preference, mainly at lower parities (three or fewer children) and by concerns about family size at higher parities. It was not so in the region where study was done. Women had 7 live female children without thought of limitation of family. Also studies in several countries, including India, have found that families without sons are less likely to use even temporary contraception than are families with sons [4-7]. Most of these studies, however, focussed exclusively on the effect of son preference and/or sex composition, on the use of temporary methods of contraception, largely ignoring sterilisation, a permanent method. Present study focussed mainly on sterilization. There were hardly any thoughts of planning, spacing in families sterilization, final end was the only decision that too probably because of health providers advocacy. Leone et al. [6] found that in Nepal, as in India, sterilisation was the predominant form of contraception, the proportion that had stopped childbearing was much higher among women whose last child was a boy than among women whose last child was a girl. Hussain et al. [4] found in Pakistan that both son preference and parity had an influence such that women stopped childbearing when they had either at least one son or three daughters. In the present study it was found that women had sterilization mostly after 3 male children. Others have also reported that this pattern which has persisted, and the likelihood of using sterilisation was positively associated with an increase in the number of sons at all parities [7-9]. In the present study, only few had sterilization, that too after 3 male live children.

Family planning represented an opportunity for women to pursue additional education and participated in public life, including paid employment. Smaller families allowed parents to invest more in each child. Children with fewer siblings tended to stay in school longer than those with many siblings. Planning family size is key to slowing we unsustainable population growth and the resulting negative impacts on the economy, environment, and national and regional development efforts. All these aspects need to be understood by communities with scarce resources. Also there is evidence that women who had more than 4 children were at increased risk of maternal mortality. Planning family provided an opportunity for women to pursue additional education and participate in public life and employment. Additionally, having smaller families allowed parents to invest more in each child. Planning family helped people have the desired number of

\section{References}

1 Park k (2011) Demography and family planning. Text book of preventive and social medicine, 21stEdition: Jabalpur, M/s Banarsidas Bhanot Publishers; 443,445,447,454.

2 Koranne P, Wahane A (2014) An analysis of awareness and utilization of contraceptives amongst married woman attending a tertiary care hospital in maharashtra, India. Natl J Community Med 5: 373-377.

3 Edmeades J, Pande RP, Falle T, Krishnan S (2011) Son preference and sterilization use among young married women in two slums in Bengaluru city, India. Glob Public Health 6: 407-420.

4 Hussain R, Fikree FF, Berendes HW (2000) The role of son preference children, which as a result improved the health of mothers and families and contributed to the nation's social and economic development [10]. It has been reported that families may want one daughter, very few wanted more than that and most definitely wanted at least one or two sons. Women with this combination were, $42 \%$ less likely to report having wanted another child relative to those with three girls. In a study, women with two or more boys and no girls or those with two girls and one boy were significantly and considerably less likely to want another child, respectively (64\% and $84 \%$ ). Saleem et al. [11] reported that the husband's desire for more children, a preference for the sex of the next child, and the woman's poor education attainment level were the main barriers of large families as appeared in the present study also. Many women in villages did not feel planning family was important and children were god given. Sons were essential for family name for future of family.

In a community based cross sectional study more than $92.2 \%$ had negative opinion towards male sterilization, like weakness following male sterilization [12]. In the study by Saba et al. [12] of all with contraception needy $72 \%$ had undergone sterilization. It is essential that awareness is created in women of such remote communities where women do not accept sterilization even after 5-6 children. In FGDs women did not come out with many answers but said children are god given, help the family, men get weakness if undergo vasectomy. They had to do hard work so should not undergo vasectomy [13-16].

Literacy, number of living children and number of living male children influenced the family size norms and unmet needs. But it is not obvious whether they even think of planned family. The reasons have to be analyzed to help the communities, government in formulation of appropriate policies and desired approaches.

\section{Acknowledgement}

We are grateful to everyone at British Columbia University, especially Dr. Shafik, Professor \& Associate Dean, Social Accountability, School of Osteopathic Medicine, University of the incarnate Word. Indo Canadian Shastri Institute, Broadway, Canada for the support for this study. Our gratefulness is also due to the women and communities of villages of Melghat region where the study has been done.

in reproductive behaviour in Pakistan. Bull World Health Organ 78 : 379-388

5 Yount KM, Langsten R, Hill K (2000) The effect of gender preference on contraceptive use and fertility in rural Egypt. Stud Fam Plann 31: 290-300.

6 Leone T, Matthews Z, Dalla Zuanna G (2003) Impact and determinants of sex preference in Nepal. Int Fam Plan Perspect 29: 69-75.

7 Jayaraman A, Mishra V, Arnold F. DHS working papers no. 40. Calverton, MD: Macro International; 2008. The effect of family size and composition on fertility desires, contraceptive adoption, and method choice in South Asia. p: 26.

8 Thind A (2005) Female sterilization in rural Bihar: What are the acceptor characteristics? J Fam Plann Reprod Health Care 31: 34-36. 
9 Edmeades J, MacQuarrie K, Pande R, Malhotra A (2008) Son preference, family composition and women's reproductive choices in Madhya Pradesh, India. Paper presented at the 2010 Annual Meeting of the Population Association of America; April 2010; New Orleans, Louisiana 17-19.

10 Family Planning Module (2017) An overview of population and family planning.

11 Saleem A, Pasha GR (2008) Women's reproductive autonomy and barriers to contraceptive use in Pakistan. Eur J Contracept Reprod Health Care 13: 83-89.
12 Saba H, Kishore K (2014) A Study to evaluate the factors influencing on Family planning practices among urban married women in Bangalore. IOSR J Dental and Med Sci (IOSR-JDMS) 13: 25-33.

13 Pathak KB, Ram F. Fertility change in India: some facts and prospects.

14 Every Day, Every Minute, A woman dies giving birth.

15 Family planning/Contraception (2017).

16 Son preference and contraceptive use among different parity women in northern India. 